\title{
Solar Radiation Transmittance Characteristics of Textile Woven Fabrics suitable for Greenhouse covering Materials
}

\author{
Amal Ray ${ }^{1}$ (D) $\cdot$ Subrata Ghosh $^{1} \cdot$ Niranjan Bhowmick $^{1}$
}

Received: 29 January 2021 / Accepted: 6 August 2021/Published online: 22 November 2021

(C) The Author(s) 2021

\begin{abstract}
Nowadays, greenhouse covering materials have a vital role in terms of a protective cultivation process. Many farmers use polyfilms, rigid or semi-rigid plastic panels, and glazing materials as greenhouse covering materials in the present scenario. However, these plastic covering materials are known for their high cost, short service life, and cause of harmful environment. Solar transmittance property is one of the main criteria for choosing any greenhouse covering materials. This study prepares various woven fabrics made of polyester, cotton, and polyester-cotton blend yarns. Their solar transmittance characteristic is analyzed to develop fabric and compare it with a polyethylene film already used as a greenhouse cladding material to substitute for plastic materials. The solar transmission of polyester fabric is achieved as high as $70 \%$ in the photosynthesis active radiation, suitable for a commercial greenhouse material. In addition, the polyester fabric has tensile strength and extension much higher than that of commercial plastic greenhouse material.
\end{abstract}

Keywords Agro-textile $\cdot$ Cover factor $\cdot$ Tensile strength . Solar transmittance $\cdot$ Spectrophotometer

\section{Introduction}

A recently released Fourth Annual Global Food Crisis Report (GRFC 2020) shows that the world's population is growing exponentially, and more urban areas would be

Amal Ray

textile.amal@gmail.com

1 Department of textile technology, Dr B R Ambedkar National Institute of Technology, Jalandhar 144011, Punjab, India expanded for habitation. As a result, required land for cultivation reduces continuously, and the food production has increased only arithmetically despite food availability per capita decreased [1]. In order to increase efficient crop production and satisfy the global demand for food, vegetables, flowers, and other horticultural crops as a solution, the protected cultivation process had to be adopted [2]. Solar radiation is one of the most important factors for plant growth. Plant leaves absorb solar radiation and use this as an energy source for photosynthesis activity [3]. It was estimated that around $86 \%$ of total energy in radiation comes from the sun in wavelengths between 300 and $1500 \mathrm{~nm}$. In the main wavelength, ultraviolet radiation (UV) $(300-400 \mathrm{~nm})$ constitutes around $8 \%$ of the total amount, photosynthesis active radiation or PAR (400-700 $\mathrm{nm}$ ) around 40\%, and the near-infrared spectrum or N-IR (700-1100 $\mathrm{nm}$ ) around 39\%. The PAR radiation makes up less than half of the sun's total energy [4]. UV radiation has a short wavelength and high energy compared to VIS (visible wavelength) or PAR and N-IR. Normally, UV radiation is known as harmful radiation that not takes participants in photosynthesis. To some extent, UV radiation helps increase the strength of the stem cell and germination at the early stage of plant growth [5]. PAR wavelength is responsible for photosynthesis activity and infrared radiation responsible for maintaining the heat balance inside the greenhouse [6]. The greenhouse is the closed structure that creates a favorable condition by trapping the short-wave solar radiation and converting it into long-wavelength thermal radiation to create a microclimate for crop production. Also, greenhouse technology offers and ensures plant and plant protection for specific purposes maintaining quality by eliminating fluctuations and environmental control [7]. However, the greenhouse cultivation process gives higher profitability by growing 
higher quality crops in short periods with a minimum land requirement, water, and other resources. Also, it is protected from hail, snow, strong wind, heavy rainfall, and adverse climatic condition. However, most of the farmers are not familiar with the importance of using greenhouse covering materials yet. Due to a lack of proper knowledge of greenhouse techniques and high initial investment cost in the greenhouse cultivation process, many cultivators may not apply this method in agricultural fields. Today various types of plastic greenhouse covering materials are available in the market. These materials are glass, rigid panel, thin films, ultra-thermic LDPE or HDPE (low- or high-density polyethylene) films with surface finishing with special additives such as UV-blocking N-IR-blocking fluorescent [8, 9]. In contrast, many disadvantages have been found in these polymeric films. Also, it was unknown about the accurate spectral radiative properties of commercially available polymeric covering materials. These films' main features are added by surface additive to get anti-drip or anti-fog effect properties [10]. Generally, polyfilms are known as water- and air-proof materials. However, plants need regular ventilation and watering for better growth. Farther more, the accumulation of condensed moisture on plastic films is the main reason for the fungal disease [11]. Although polyfilms are high cost due to included surface additive and finishing also low service life, another big problem is the waste of polymeric materials after the cultivation season, which can cause soil and water pollution. Due to high exposure to sunlight for a long time and aggregation of dust and water droplets on the plastic films' surface, a study has shown that PAR radiation's total transmittance decreases by $15 \%$ and causes serious concerns about plant growth [12]. However, the textile fabric has unique properties and plays an important role in day-to-day life, not only for aesthetic purposes but also for versatile applications in technical textile and the agriculture sector. While the solar radiation hits the surface of a textile fabric, some parts of the radiation are absorbed, some part of the radiation is reflected, and remaining part of the radiation is transmitted through the fabric, as seen in Fig. 1 [13]. However, light transmission is the main potential characteristic of woven fabric, but there was very little known yet. Only a few experimental results in UV protection engineered fabric are available on the radiometric properties of textile woven fabric. But there was a very limited amount of information available regarding the radiometric behavior of a textile. When the textile fabric is considered, a greenhouse covering material is a necessary concern about increasing the PAR transmittance because of the spectral distribution of solar energy, the PAR range is essential for the photosynthesis activity of the plants [14]. The optimum level of PAR radiation reaches the plant's leaf and being used for enhancing the physiological behavior of plants [15]. A. Petchsuk et al. investigated that the most promising result in a greenhouse covering materials PAR transmission should be maintained in the range of 62.6 to $78.9 \%$. Generally, PAR transmittance should be more than $70 \%$, UV transmission should be less than $30 \%$, and the N-IR reflection at more than $17.5 \%$ [16]. The textile woven fabric has excellent environment resistance and durability capacity. It is more resistant to mechanical factors due to the flexibility with the possibilities to transmittance the selective solar radiation. There are many advantages to use the textile covering materials such as protecting the crop from harsh climatic conditions, protecting the soil from drying out, extending the growing season of the plants, and reducing the uses of fertilizer, pesticide, and water. However, the textile fabrics are easy to handle, excellent mechanical and thermal properties, and good processability according to their application and enduse area [17]. The aim of this study is to achieve higher transmission in the PAR region and optimum transmission in the UV region by a textile fabric that can be useful as greenhouse cladding materials. Therefore, the decision has been made to adopt three different types of fiber composition such as polyester, cotton, and blends of polyestercotton (65:35) and into each fiber composition has twelve different fabric sample within the same construction parameters, the same fabric design, and the same warp settings but different by the cover factor due to changes in weft settings. The properties of woven fabrics, such as areal density, thickness, and cover factor, are directly related to solar radiation's transmittance effect through the woven fabric [18, 19]. Based on this information, textile fabrics are selected to design the greenhouse covering materials that may be useful for a more sustainable environment in the small- to medium-sized greenhouse cultivation process.

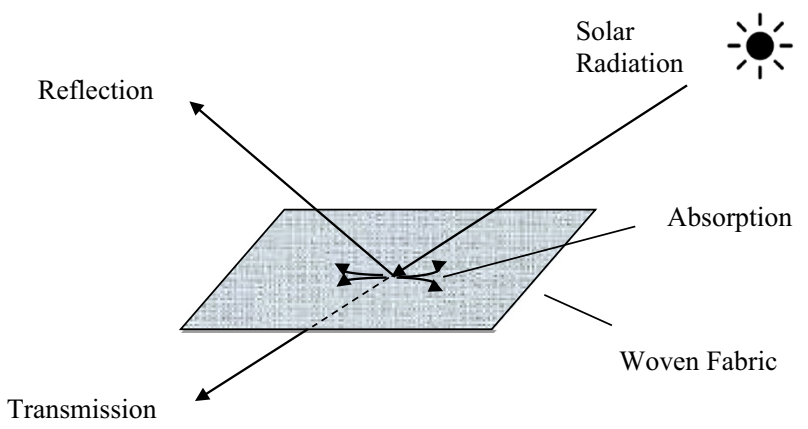

Fig. 1 Isometric figure of solar radiation transmission through the woven fabric 


\section{Materials and Methods}

\section{Materials}

In this study, a total of thirty-six woven fabrics were prepared in a miniature rapier loom (SL8900 CCI Tech) from Northern India Textile Research Association (NITRA), Ghaziabad (UP), India. Three different types of span yarns developed all fabrics samples are used in this study are prepared at Vardhman textile Ltd., viz. polyester (PET), cotton (CO), and polyester-cotton (PC) blend (65:35) of the same linear density 7.6 tex, keeping warp density (33 threads $/ \mathrm{cm}$ ) constant. The weft density of the fabrics was varying by keeping the warp density constant. The details of the samples are shown in Table 1. The polyester fabrics are coded as PET-1 to 12, polyester-cotton blended (65:35) fabrics are coded as PC-1 to 12 , and cotton fabrics are coded as CO-1 to 12 . Polyester and cotton fabrics are selected for this study because they are readily and commercially available and have good tensile strength and low extension compared to conventional polyethylene (PE) films as greenhouse as covering material [20]. During the fabric preparation, the decision has been taken to all samples made in the plain weave design because plain fabric structure has high interlacement point gives higher tensile strength than twill or satin fabric structure [21]. Commercially available UV-stabilized polyethylene film of 200-micron thickness was collected from the Center of Excellence for Vegetables (Indo-Israel collaboration), Jalandhar, India. This greenhouse plastic material was used for comparison with the properties of the prepared fabric sample. Eighteen different types of commercial fabric were collected from the market and tested their light transmission properties. The data of light transmittance of these fabrics are compared with that of polyfilm used in an IndoIsrael agriculture projects at Jalandhar in India, which is a well-established greenhouse covering material. Then finally, the idea of setting the tentative values of construction parameters for the prepared samples has been set as per the data of light transmittance [9]. Before the testing, all samples were conditioning at a standard atmosphere temperature of $27 \pm 2{ }^{\circ} \mathrm{C}$ and relative humidity of $65 \pm 2 \%$ for $24 \mathrm{~h}$. According to the sample variation, the number of experimental readings was determined to achieve a confidence limit within the $95 \%$ level.

\section{Methods}

\section{Measurement of Physical Properties of the Fabric}

In this study, the areal density was measured by ASTM D 3776 standard testing methods. The warp and weft thread density of the fabric was measured according to ASTM D 3775 standard testing methods by using a digital counter. The thickness digital thickness tester was used for measuring the fabric thickness as per standard methods BS EN ISO 9073-2 applying initial pressure at $0.25 \mathrm{kPa}$ for 10 to $30 \mathrm{~s}$ during testing [22].

\section{Measurement of the Cover Factor of Fabric}

The cover factor defined as the ratio of the area is covered by yarn and the actual total area of the fabric. The deciding factor is the area covered by fibers or yarns. It is also noted that the cover factor has highly influenced the light transmission property of the woven fabrics. A Leica LAS Image Analyzer microscope was used for capturing surface images of fabric samples with 20X magnification. The image consisted of $990 \times 713$ pixels, each value having a value between 0 and 255 representing the brightness of that pixel. For each fabric, the illumination was adjusted such that the peak pixel values, corresponding to open areas in the fabric, had an average value of approximately 250 . A cutoff intensity value of 125 was used to separate the pixels representing open areas from those representing areas covered by yarns or fibers. Therefore, the images were digitized and then analyzed by ImageJ software [23]. At first, the number of pixels falling above and below the cutoff value is determined. Then, the covered area percentage was calculated. Reported cover percentages are based on the average of five images per fabric. The choice of an intensity value of 125 to define the edge of fibers is based on the assumption that transmission of light through the fibers itself is negligible, which is not always the case. The interlaced structure of the fibers results in only a fraction of the fibers observed in a given microscope image being in sharp focus with clearly defined edges.

Conversely, fibers out of focus have blurred edges, making it difficult to determine the edge position precisely. Based on these limitations, the estimated accuracy of the cover measurement was on the order of several percent due to dependence on the choice of the threshold value separating dark from light pixels. Therefore, the fabric sample is supplied with light from the backside, as shown in Fig. 2. The average cover factor value of the woven fabric was calculated from 5 readings of each sample, and the cover factor percentage was determined by Eq. (1) [24].

$\mathrm{CF} \%=\frac{\left(A_{i}-A_{t}\right)}{A_{i}} \times 100 \%$

$A_{i}$ is the total area of the woven fabric, and $A_{t}$ is the pore size of the textile fabric using the image analysis tool. Then cover factor of the woven fabric could be directly calculated in percentage using Eq. (1). The following steps are used to evaluate the cover factor of fabric by 
Table 1 The construction and physical properties of woven fabrics prepared

\begin{tabular}{|c|c|c|c|c|c|c|}
\hline Fabric code & $\begin{array}{l}\text { Weft density (threads/ } \\
\mathrm{cm})\end{array}$ & $\begin{array}{l}\text { Weight per unit area } \\
\left(\mathrm{g} \mathrm{m}^{-2}\right)\end{array}$ & $\begin{array}{l}\text { Thickness } \\
(\mathrm{mm})\end{array}$ & $\begin{array}{l}\text { Cover } \\
\text { factor }\end{array}$ & SD & SE \\
\hline $\begin{array}{l}\text { PE film (Sample collected from Indo-Israel } \\
\text { Projects) }\end{array}$ & - & 200 & 0.2 & - & & \\
\hline PET-1 & 34 & 54.92 & 0.1025 & 20.45 & 0.37 & 0.013 \\
\hline PET-2 & 32.5 & 53.41 & 0.1024 & 20.12 & 0.30 & 0.011 \\
\hline PET-3 & 31 & 52.26 & 0.1024 & 19.77 & 0.30 & 0.011 \\
\hline PET-4 & 30.5 & 51.11 & 0.1023 & 19.42 & 0.30 & 0.011 \\
\hline PET-5 & 28.5 & 49.96 & 0.1022 & 18.66 & 0.32 & 0.011 \\
\hline PET-6 & 27 & 48.81 & 0.1022 & 18.30 & 0.33 & 0.012 \\
\hline PET-7 & 25.5 & 47.66 & 0.1021 & 17.96 & 0.33 & 0.012 \\
\hline PET-8 & 24 & 46.52 & 0.1021 & 17.63 & 0.35 & 0.012 \\
\hline PET-9 & 22 & 45.37 & 0.1020 & 16.86 & 0.33 & 0.012 \\
\hline PET-10 & 20.5 & 44.22 & 0.1019 & 16.52 & 0.33 & 0.012 \\
\hline PET-11 & 19 & 43.07 & 0.1019 & 16.16 & 0.32 & 0.011 \\
\hline PET-12 & 17.5 & 41.92 & 0.1018 & 15.81 & 0.33 & 0.012 \\
\hline PC-1 & 34 & 55.31 & 0.1034 & 20.64 & 0.73 & 0.026 \\
\hline PC-2 & 32.5 & 54.20 & 0.1033 & 20.32 & 0.73 & 0.026 \\
\hline PC-3 & 31 & 52.87 & 0.1032 & 19.99 & 0.73 & 0.026 \\
\hline PC-4 & 30.5 & 51.59 & 0.1031 & 19.63 & 0.73 & 0.026 \\
\hline PC-5 & 28.5 & 50.40 & 0.1030 & 18.83 & 0.73 & 0.026 \\
\hline PC-6 & 27 & 49.03 & 0.1029 & 18.50 & 0.73 & 0.026 \\
\hline PC-7 & 25.5 & 47.84 & 0.1029 & 18.13 & 0.73 & 0.026 \\
\hline PC-8 & 24 & 46.66 & 0.1028 & 17.84 & 0.73 & 0.026 \\
\hline PC-9 & 22 & 45.47 & 0.1027 & 17.01 & 0.73 & 0.026 \\
\hline PC-10 & 20.5 & 44.29 & 0.1027 & 16.68 & 0.73 & 0.026 \\
\hline PC-11 & 19 & 43.10 & 0.1026 & 16.34 & 0.73 & 0.026 \\
\hline PC-12 & 17.5 & 41.82 & 0.1026 & 15.99 & 0.73 & 0.026 \\
\hline CO-1 & 34 & 55.18 & 0.1048 & 21.04 & 0.66 & 0.023 \\
\hline $\mathrm{CO}-2$ & 32.5 & 53.99 & 0.1046 & 20.70 & 0.66 & 0.023 \\
\hline $\mathrm{CO}-3$ & 31 & 52.80 & 0.1044 & 20.34 & 0.66 & 0.023 \\
\hline CO-4 & 30.5 & 51.60 & 0.1043 & 19.98 & 0.66 & 0.023 \\
\hline $\mathrm{CO}-5$ & 28.5 & 50.43 & 0.1041 & 19.20 & 0.66 & 0.023 \\
\hline CO-6 & 27 & 49.24 & 0.1040 & 18.86 & 0.66 & 0.023 \\
\hline $\mathrm{CO}-7$ & 25.5 & 48.05 & 0.1039 & 18.50 & 0.66 & 0.023 \\
\hline CO-8 & 24 & 46.86 & 0.1038 & 18.14 & 0.66 & 0.023 \\
\hline CO-9 & 22 & 45.67 & 0.1037 & 17.36 & 0.66 & 0.023 \\
\hline CO-10 & 20.5 & 44.48 & 0.1036 & 17.03 & 0.66 & 0.023 \\
\hline CO-11 & 19 & 43.29 & 0.1035 & 16.66 & 0.66 & 0.023 \\
\hline $\mathrm{CO}-12$ & 17.5 & 42.09 & 0.1034 & 16.38 & 0.66 & 0.023 \\
\hline
\end{tabular}

*PET, polyester; PC, polyester-cotton blends; CO, cotton; SD, standard deviation; SE, standard error

using image-J software. In the first step, the fabric sample place into the Leica LAS Image Analyzer microscope with 20X magnification, and the focus is adjusted to get a clear RGB image shown in Fig. 2a. In the second step, the original image is uploaded to ImageJ software and converted from the RGB image to an eight-bit gray image, as shown in Fig. 2b. Then, image enhancement was done by cropping the 8-bit gray image in $777 \times 553$ dimensions to ensure that the pictures were more precise and freer from noise. In the third step, 8-bit gray images are converted to back and white binary images, as shown in Fig. 2c. Finally, a data analysis process was conducted to 


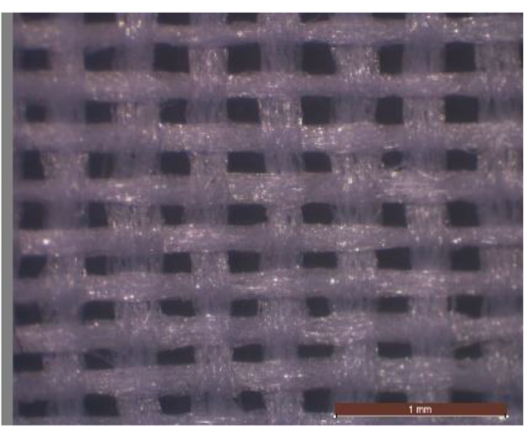

(a)

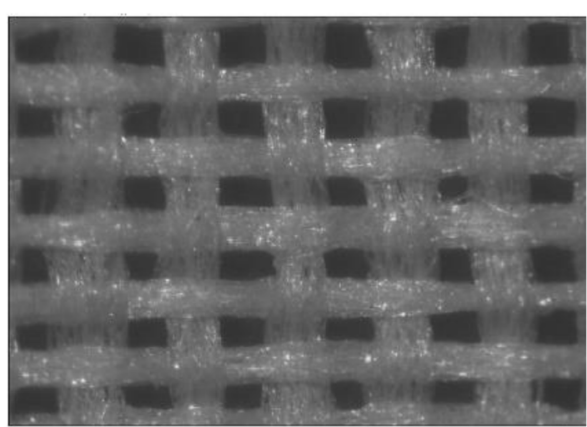

(b)

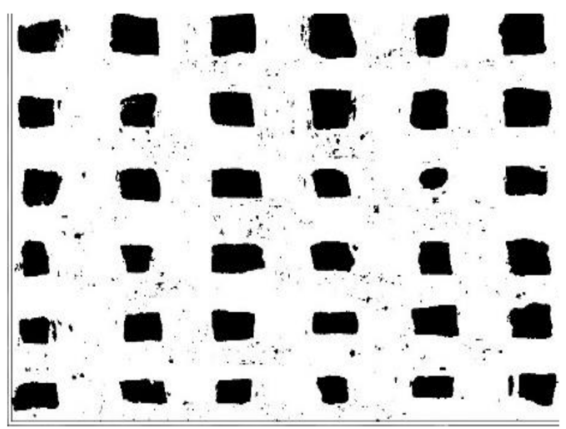

(c)

Fig. 2 Optical microscopic images of the woven fabrics used for image analysis: a original image of polyester (PET-12) fabric, b 8-bit cropped image $(771 \times 502 \mathrm{~mm})$ of polyester fabric, and $\mathbf{c}$ binarization of the same cropped image

calculate the black region area $\left(A_{t}\right)$ and the total area of the image $\left(A_{i}\right)$ to determine the cover factor as per Eq. (1).

\section{Measurement of Radiometric Properties of Sample}

Shimadzu UV-2600 spectrophotometer was used as the measuring equipment for the optical properties of different fabrics. The measured wavelength range can be extended from 200 to $1400 \mathrm{~nm}$. The tested wavelength was selected for the test purpose from 280 to $1100 \mathrm{~nm}$ to cover up to UV, PAR, and N-IR. The measuring spectrums were included in UV radiation (220-400 nm), PAR radiation $(400-700 \mathrm{~nm})$, and $\mathrm{N}-\mathrm{IR}$ radiation $(700-1100 \mathrm{~nm})$ to evaluate the transmittance behavior of the fabric samples in these wavelength regions [25]. For evaluating the transmission characteristics of the textiles, a sample size of $80 \mathrm{~mm}$ length and $40 \mathrm{~mm}$ breadth was used. This testing instrument was equipped with a two-detected double-beam system photomultiplier tube detector used for the UV, VIS wavelength region, and a low-temperature lead-sulfide sensor for the N-IR wavelength region. These two detectors were connected with an integrated sphere, and the inner surface of the sphere is coated with barium sulfate for evaluating the total transmittance of the scattering materials. The transmission, reflection, and absorption percentages of UV, PAR, and IR in the solar spectrum were calculated according to the equation: 2 to 9 in the EN 410 standard testing method. The percentage of direct and diffuse transmission in total solar radiation can be measured according to TS EN 1400 Part-B standard testing methods. In the UV region, the UV-C region is excluded because much of UV-C absorbed by the ozone layer and did not reach the terrestrial earth surface [26]. Equation (2) determines the transmittance of solar radiation through the fabric sample. The UV, PAR, and N-IR transmittance is $T$ for perpendicularly incident solar radiation, which can be defined as
$T=\frac{\sum_{\lambda=200 \mathrm{~nm}}^{\lambda=1100 \mathrm{~nm}} T_{\lambda} P_{\lambda} D_{\lambda} \Delta \lambda}{\sum_{\lambda=200 \mathrm{~nm}}^{\lambda=1100} P_{\lambda} D_{\lambda} \Delta \lambda}$

where $T$ is solar transmittance, $P_{\lambda}$ is direct normal spectral irradiance at $\lambda\left(\mathrm{W} \mathrm{m}^{-2} \mathrm{~nm}\right), D_{\lambda}$ is an account for the relative photosynthetic yield in different wavelengths, $T_{\lambda}$ is the measured transitional spectrum of the fabric or spectral transmission, $\lambda$ is the wavelength $(\mathrm{nm})$, and $\Delta \lambda$ is the bandwidth (nm) quantity of solar energy required to yield.

$R=\frac{\sum_{\lambda=200 \mathrm{~nm}}^{\lambda=1100 \mathrm{~nm}} R_{\lambda} P_{\lambda} D_{\lambda} \Delta \lambda}{\sum_{\lambda=200 \mathrm{~nm}}^{\lambda=1100 \mathrm{~nm}} P_{\lambda} D_{\lambda} \Delta \lambda}$

Similarly, $R$ is solar reflectance, and $R_{\lambda}$ is spectral reflectivity

$A=\frac{\sum_{\lambda=200 \mathrm{~nm}}^{\lambda=1100 \mathrm{~nm}} A_{\lambda} P_{\lambda} D_{\lambda} \Delta \lambda}{\sum_{\lambda=200 \mathrm{~nm}}^{\lambda=1100} P_{\lambda} D_{\lambda} \Delta \lambda}$

Similarly, the same as $A$ is the solar absorbance and $A_{\lambda}$ is spectral absorbency.

According to the relationship of energy conversation law, if $I_{0}$ is light intensity without materials, $I_{T}$ is the solar intensity after transmittance, $I_{A}$ is the solar intensity after absorbance by the materials, and $I_{R}$ is the solar intensity after reflected by the materials, then the total of average solar transmittance, average solar reflectance, and average solar absorption is one at the same wavelength [25].

$I_{0}=I_{T}+I_{A}+I_{R}$

$1=I_{T} / I_{0}+I_{A} / I_{0}+I_{R} / I_{0}$

The average transmittance is $T=I_{T} / I_{0}$, average absorbance $A=I_{A} / I_{0}$, and average reflectance $R=I_{R} / I_{0}$.

$1=T+A+R$

Or $R=1-(T+A)$

According to Beer-Lambert law, the relation of average 
solar transmittance $(T)$ and absorbance $(A)$ uses the following equation:

$A=\log _{10} \frac{1}{T}$

Then from Eqs. (8) and (9), the average solar reflectance and absorbance were determined.

\section{Measurement of Thermal Conductivity}

Thermal conductivity is an essential property when we are considering fabric as greenhouse covering materials. Generally, most commercial plastic films value of the overall heat transfer coefficient has around 0.1-0.5 $\mathrm{W} \mathrm{m}{ }^{-2} \mathrm{~K}^{-1}$, which means the thermal conductance of polyethylene films is valued at around $0.33 \mathrm{~W} \mathrm{~m}^{-1} \mathrm{~K}^{-1}$ [28]. Besides, the textile fabric has a meager thermal conductive value because the textile materials have an air pocket (higher porous materials) due to the air having a low conductive capacity. The thermal conductivity of the PE film and the woven fabrics was measured as Alamdita tester in terms of $\mathrm{W} \mathrm{m}^{-1} \mathrm{~K}^{-1}$. Conduction methods and some extent of heat transfer may occur due to vapors convection and radiative heat transfer [29]. The thermal conductivity of all the fabrics samples was measured, with three readings taken for each sample. The thermal conductivity $(k)$ is calculated by using the following equation.

$k=Q L / A\left(T_{h}-T_{c}\right)$

where $Q$ is the heat flux through the specimen, $L$ is thickness $A$ is the area considered, and $T_{h}$ and $T_{c}$ are the temperatures of the hot and cold surfaces of the specimen, respectively.

\section{Evaluation of Tensile Properties}

Tensile strength is one of the important characteristics of greenhouse covering material to stand the mechanical forces driving use. This examination provides an idea of the service life and performance of the covering materials. The tensile strength was measured on a computerized Universal Testing Machine (UTM) in both warp and weft directions following ASTM D5035-06 standard strip testing methods. The fabric sample was tested with a length of gage length of $200 \mathrm{~mm}$ and a crosshead speed of $100 \mathrm{~mm} /$ $\min [30]$.

One-way analysis of variance (ANOVA) was employed to test the statistical significance of the differences in the transmittance of three different fabric types with the same construction parameters. Considering the significance level $P<0.05$, data show UV, PAR, and IR region transmittance. The solar transmittance value depends on the areal density, thickness, cover factor, and porosity of the woven fabric [31].

\section{Results and Discussion}

\section{Physical Properties of the Woven Fabrics}

The woven fabric samples were produced by keeping warp density (33 threads/cm) constant and varying the weft density. The fabric weight per unit area, thickness, and cover factors are measured, and the results are tabulated in Table 1. It can be seen that as weft density increases, fabric weight, thickness, and cover factor of the fabrics increase, which is a normal trend [26].

\section{Solar Transmission Behaviors of the Textile Fabrics}

The solar transmission of all prepared woven samples is measured in the UV, PAR, and N-IR regions. Ultraviolet (UV) radiation is known as a harmful high-energy wavelength for plants. Still, some amount of UV radiation helps to kill the pathogens on plant leaves and allows insects to navigate the flowers during pollination [5]. Photosynthetic active radiation (PAR) is most important for the greenhouse cultivation process by controlling the physiological behavior of plants. Red and blue light is absorbed mainly by plant leaves within the PAR radiation and serves as critical spectral components that promote photosynthesis and plant growth[32]. Finally, the infrared (IR) radiation controls the heat balance and maintains the ambient temperature inside the greenhouse [33].

In this experiment, wavelength set in the range of 200 to $1100 \mathrm{~nm}$ to cover the UV, PAR, and N-IR (near-infrared) region, and results are reported in Fig. 3. Here, Fig. 3a shows the solar transmittance of PE film (consider as count as reference sample), Fig. 3b shows the solar transmittance of all the polyester fabric, Fig. 3c shows the solar transmittance of all polyester-cotton blend fabric, and Fig. 3d shows the solar transmittance of all cotton fabric in 200-1100 nm wavelength range to cover the whole UV, PAR, and N-IR region. It can be seen that PE polyfilm has a maximum of $13 \%$ solar transmittance in the UV region and around $80 \%$ to $82 \%$ solar transmittance in PAR and $\mathrm{N}$-IR regions, respectively. In comparison to $\mathrm{PE}$ films, it can be seen that polyester fabric samples PET: 10, 11, and 12 have a transmittance of more than $70 \%$ in the PAR region, but the solar transmittance of the PET fabrics declines with fabric density and thickness for similar construction due to reduction on voids space. It also depends on the different types of fibers and cloth cover. The woven fabric with the minimum number of yarns in the warp and weft has high light transmittance. However, 
the fabric weight and thickness are having an impact on light transmission. Lightweight and thinner textiles offer higher PAR light transmittance characteristics [34]. The polyester woven fabric has been a higher rate of solar transmittance than the other fabrics with similar construction parameters in the PAR region. Besides, the polyestercotton blend found a moderate solar transmittance capacity of around $60 \%$ in the PAR region. But cotton fabric shows inferior performance in PAR transmittance ability around $50 \%$ within the same construction parameter. Therefore, polyester fabrics are superior to cotton and blended fabrics in terms of transmission in the PAR region, which is very useful for photosynthesis and also it is helpful for plant growth in the greenhouse cultivation process. These may be due to the translucent nature of the polyester fabric.

In the N-IR region, the trends of the graph show (Fig. 3) that the polyethylene film has a maximum of $82 \%$ transmittance that is comparatively higher than that of the textile fabrics such as $76 \%, 63 \%$, and $52 \%$ for PET, PC (PET/ $\mathrm{CO}$ ) blend, and $\mathrm{CO}$, respectively. According to our study, light transmittance is the primary requirement. Polyester (PET-12) has found 54.38\% transmittance in UV region, then increases in 74.74 in PAR region, and increases $76.09 \%$ in N-IR region, which is quite similar as PE films graph trends follow. Therefore, the best structure polyester fabrics (PET-12) constructed with areal density 54.92, fabric thickness 0.1025 , and fabric cover $20.45 \%$, shown in Table 1 . This polyester fabric is excellent for maintaining the transmittance value of nearly $76 \%$, close to the conventional polyethylene films used as greenhouse covering materials.

\section{Effect of Nature of Textile Fiber on Solar Transmission Properties}

Photosynthetic active radiation (PAR, 400-700 nm) is the most important radiometric property for any greenhouse covering materials because it is essential for photosynthesis and plant growth. However, many textile fibers are considered translucent or semi-transparent in nature, but the ability to transmit sunlight mainly depends on the chemical structure of the fiber. In these current analyses, fibers with different chemical structures such as polyester and cotton and their blends on the solar transmission are evaluated.

The solar transmittance property of the polyethylene films and all three fabric samples having the same construction parameters is shown in Fig. 4. It can be seen that the transmittance of the PE film is lowest in the UV region but highest in PAR and N-IR regions. $100 \%$ polyester fabric shows higher transmission than cotton and blended fabrics in all UV, PAR, and N-IR regions. The polyester fabric allows necessary UV radiation for insect control and
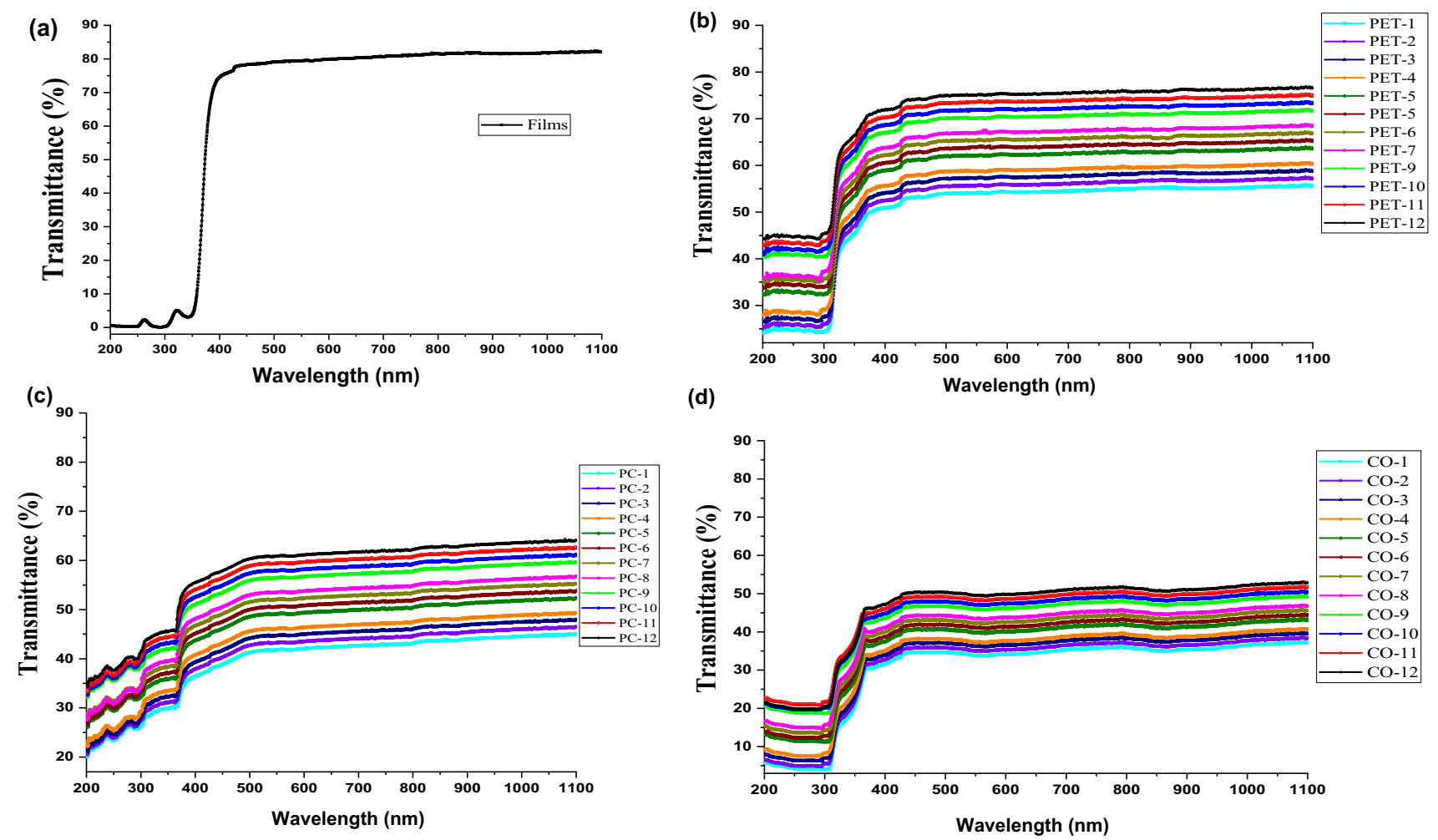

Fig. 3 Transmittance properties of a polyethylene film, b polyester fabric, $\mathbf{c}$ polyester-cotton blend fabric, and $\mathbf{d}$ cotton fabric in the region of UV, PAR, and N-IR 
enables PAR radiation for sufficient photosynthesis and growth of the plant [33]. Comparing these experimental results in woven fabric samples of individual fiber composition found that there are hardly any differences in the same construction parameter of PET-12, PC-12, and CO-12 fabrics. But fibers nature may play an important role in transmission. From Fig. 4, it can be seen that the polyester (PET-12) and blends of polyester-cotton (PC-12) and cotton (CO-12) maximum solar transmission are $76 \%$, $63 \%$, and $52 \%$, respectively, because the polyester fiber is known as more translucent aromatic molecules which contain conjugated polymeric chains carbon-oxygen double bond, which is part of the ester group in these molecules, unlike natural fiber. Also, in the polyester spun yarn is less hairiness as compared to cotton yarn in fabric. Besides, cotton fiber composition, which had less transmission, may influence the hairiness of the yarn on the solar properties of the fabric, especially at PAR and N-IR regions. The presence of gray materials such as wax and pectin in cotton fiber may decrease the solar transmittance. Also, increasing the hairiness one of the reasons for decreasing the solar transmittance properties of the fabric. Thus, the chemical structure and hairiness of the yarn influence solar properties [34, 35]. However, there was evidence that the yarn chemical structure affected the woven fabric solar properties when the datasets were examined individually.

\section{Effect of Cover Factor, Thickness and Areal Weight of Textile Fabrics on Solar Transmission}

The areal density, thickness, cover factor, and porosity can affect the solar transmission behaviors of the textile fabrics.
Effects of these parameters on solar transmission behaviors are investigated, and results are shown in Fig. 5. From the figure, it can be assessed that areal density $\left(\mathrm{g} \mathrm{m}^{-2}\right)$ and the cover factor are inversely proportional to the solar transmittance. As the weight of the fabric and the cover factor increase, the solar transmission gradually decreases (Fig. 5a, c). However, the thickness drops down exponentially (Fig. 5b). The relationship between the fabric and solar transmission porosity is directly proportional to the porosity of the fabric (Fig. 5d). As the yarn gets finer, the transmittance of the fabric increases, and the reflectance of the fabric decreases. Further, the porosity of the fabric increases, the solar transmission also increases, and vice versa. The decrement rate is almost linear for all cases because higher values of these parameters are responsible for blocking more solar radiation. Also, when porosity increases, solar transmittance increases linearly for all kinds of fabric samples [37].

\section{Thermal Conductivity of Textile Fabrics}

An investigation has been carried out to investigate and compare the thermal conductivity of PE films and all three fabrics showing the highest solar transmission. Thermal conductivity $(k)$ values of the samples were measured using a thermal conductivity tester. According to Lubos Hes et al., the thermal conductivity of textile woven fabric typically ranges from 0.033 to $0.01 \mathrm{~W} \mathrm{~m}^{-1} \mathrm{~K}^{-1}$. Open air has a thermal conductivity of $0.025 \mathrm{~W} \mathrm{~m}^{-1} \mathrm{k}^{-1}$ [38]. Woven fabric with a high thermal conductivity easily lets heat pass from a hot side to a cool side. The results are shown in Table 2. It can be seen that PET-12 fabric has the lowest thermal conductivity of about $0.0218 \mathrm{~W} \mathrm{~m}^{-1} \mathrm{~K}^{-1}$,
Fig. 4 Comparison of the average solar transmittance of PE film and different fabrics

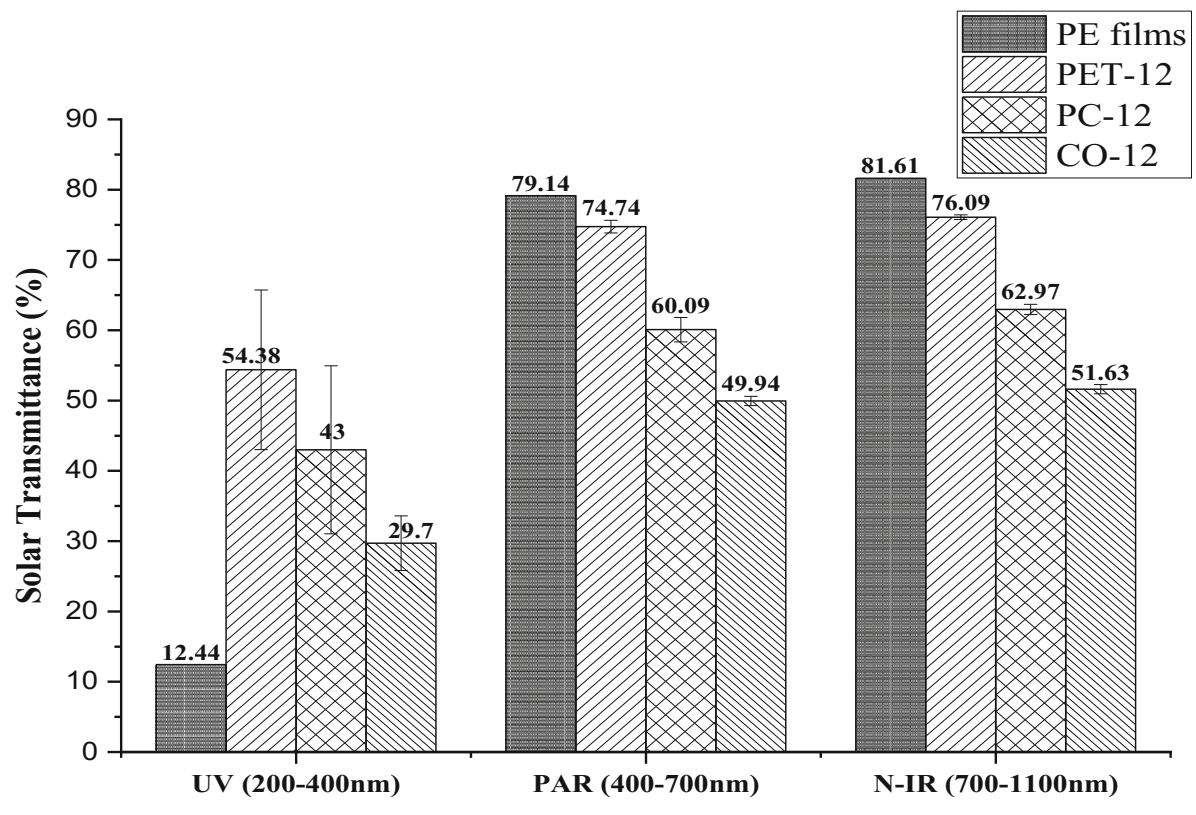


(a)

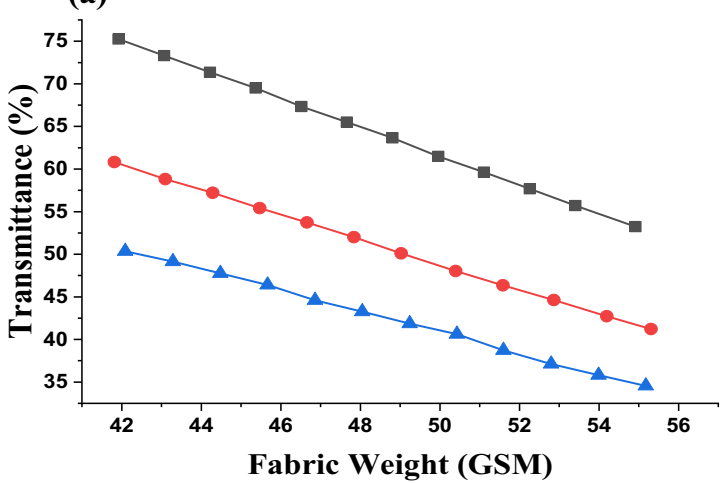

(c)

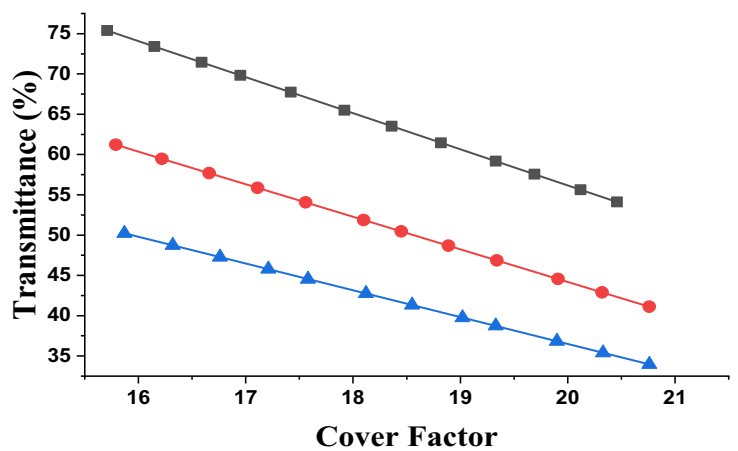

(b)

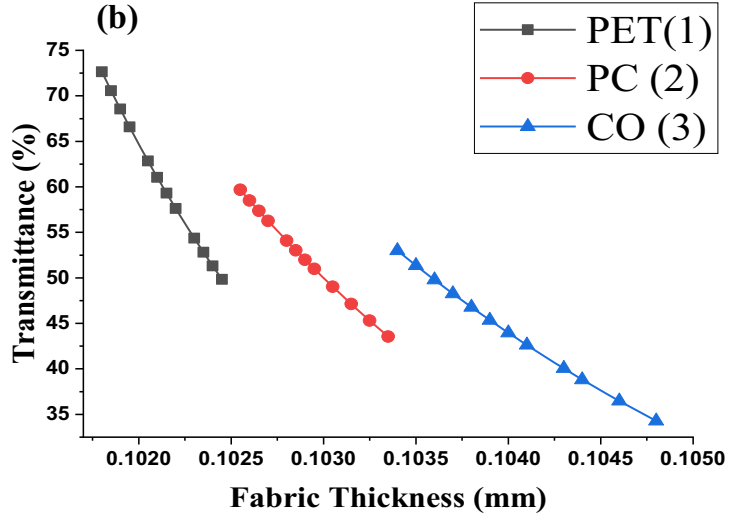

(d)

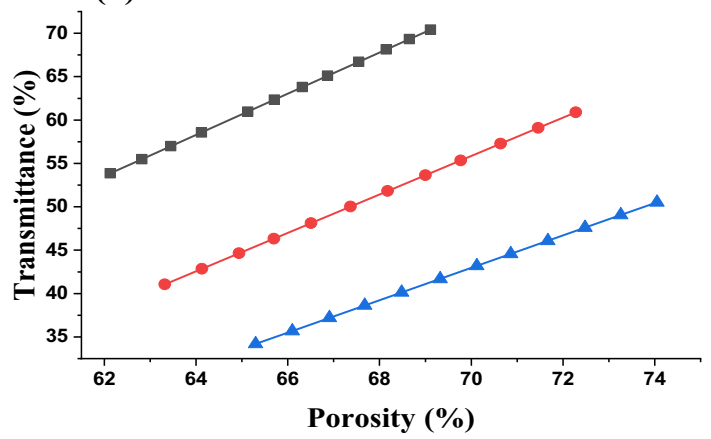

Fig. 5 Solar transmission of three different types of fabric: a effect of fabric weight, b effect of fabric thickness, $\mathbf{c}$ effect of cover factor, and d effect of porosity

Table 2 Comparison of the thermal conductivity of different covering materials

\begin{tabular}{ll}
\hline Sample & ${\text { Thermal conductivity }\left(\mathrm{W} \mathrm{m}^{-1} \mathrm{~K}^{-1}\right)}$ \\
\hline PE films (Indo-Israel Projects) & 0.0401 \\
PET-12 fabric & 0.0218 \\
PC-12 fabric & 0.0272 \\
CO-12 fabric & 0.0326 \\
\hline
\end{tabular}

though it is much below the value of PE film. Low thermal conductivity means a slower decrease in heat pass through the covering materials. Hence, textile cover reduces heat loss during the winter season. On the contrary, internal heat retention capacity is much high as compared to commercially available plastic films. As a result, the polyester fabric (PET-12) may be an alternative solution for a greenhouse covering material [39].

\section{Tensile Properties of the Textile Fabrics}

Mechanical tests reveal that the tensile properties and extension of polyethylene films are much lower than the textile fabrics, as shown in Table 3 . The polyethylene films had an absolute breaking load of 77.3 Newtons, much less than the polyester fabric. The absolute breaking load of polyester (PET-12) is six times higher than PE films. The breaking extension of PET-12 is much higher than the polyethylene films [40]. The polyester fabric (PET-12), the best sample for the solar transmittance, has been found the highest tensile strength and extension and may replace commercial polyethylene films. So, the polyester woven fabric may be used as greenhouse covering materials for field trial. 
Table 3 Comparison of tensile properties of different covering materials

\begin{tabular}{llll}
\hline Sample & Direction & Breaking load $(N)$ & Extension $(\%)$ \\
\hline PE films (Indo-Israel Projects) & - & 77.3 & 17.2 \\
PET-12 fabric & Warp & 482 & 25.13 \\
& Weft & 423.5 & 23.2 \\
PC-12 fabric & Warp & 443 & 26.59 \\
& Weft & 426 & 25.09 \\
CO-12 fabric & Warp & 268.5 & 18.2 \\
& Weft & 147 & 25.2 \\
\hline
\end{tabular}

\section{Conclusion}

In this study, a total of 36 textile woven fabrics have been prepared with polyester yarns, cotton, and their blends. The solar transmission value was evaluated, and it was found that polyester fabrics were given the best result to achieve the solar transmittance value in the range of 62.6 to $78.9 \%$ (i.e., near to the transmittance value of polyfilm). The cover factor of the woven fabric must be in the range of $16 \%$. According to this study, the polyester fabric (PET-12) exhibits the highest shown as $79 \%$ when prepared with and 17.5 threads/cm warp density and 17.5 threads/cm warp and weft density with fabric weight $41.82 \mathrm{~g} \mathrm{~m}^{-2}$, thickness $0.1026 \mathrm{~mm}$, and cover factor around $16 \%$. In addition, the tensile strength of the polyester fabric is found to be 482 Newton and breaking extension of $25.13 \%$, which was found much higher than that of the commercial polyethylene films. Therefore, the polyester fabric can be an alternative solution for commercial greenhouse covering materials. It is essential to focus on future research to develop an inexpensive shade cloth to reduce the existing problem of climate change during crop production and provide cheap covering materials to farmers with viable strategies. Furthermore, the sustainable use of textile fabric without harming the environment is a key solution for the advanced crop production process in small- or mediumscale greenhouse.

Acknowledgements The authors gratefully acknowledge the support of Department of Textile Technology, Uttar Pradesh Textile Technology Institute, Kanpur, India, for helping in the write-up of this paper.

Funding There is no financial support for performing this work.

\section{Declarations}

Conflicts of interest The authors wish to confirm that there is no conflict of interest for publishing this work.

Open Access This article is licensed under a Creative Commons Attribution 4.0 International License, which permits use, sharing, adaptation, distribution and reproduction in any medium or format, as long as you give appropriate credit to the original author(s) and the source, provide a link to the Creative Commons licence, and indicate if changes were made. The images or other third party material in this article are included in the article's Creative Commons licence, unless indicated otherwise in a credit line to the material. If material is not included in the article's Creative Commons licence and your intended use is not permitted by statutory regulation or exceeds the permitted use, you will need to obtain permission directly from the copyright holder. To view a copy of this licence, visit http://creativecommons. org/licenses/by/4.0/.

\section{References}

1. Food Security Information Network, "Global report on food crises 2020," Fao.Org, pp. 1-240, 2020, [Online]. Available: https://www. wfp.org/publications/2020-global-report-food-crises.

2. G. López-Díaz, A. Carreño-Ortega, H. Fatnassi, C. Poncet, M. Díaz-Pérez, The effect of different levels of shading in a photovoltaic greenhouse with a north-south orientation. Appl. Sci. (2020). https://doi.org/10.3390/app10030882

3. I.M. Al-Helal, A.M. Abdel-Ghany, Responses of plastic shading nets to global and diffuse PAR transfer: optical properties and evaluation. NJAS Wageningen J. Life Sci. 57(2), 125-132 (2010). https://doi.org/10.1016/j.njas.2010.02.002

4. G. Papadakis, D. Briassoulis, G. Scarascia Mugnozza, G. Vox, P. Feuilloley, J.A. Stoffers, Radiometric and thermal properties of, and testing methods for, greenhouse covering materials. J. Agric. Eng. Res. 77(1), 7-38 (2000). https://doi.org/10.1006/jaer. 2000.0525

5. M. Raviv, Y. Antignus, Invited review: UV radiation effects on pathogens and insect pests of greenhouse-grown crops. Photochem. Photobiol. 79(3), 219 (2004). https://doi.org/10.1562/ si-03-14.1

6. A.M.A.-G.I.M. Al-Helal, Energy partition and conversion of solar and thermal radiation into sensible and latent heat in a greenhouse under arid conditions. Energy Build. 43(7), 1740-1747 (2011). https://doi.org/10.1016/j.enbuild.2011.03.017

7. K.S. Kumar, K.N. Tiwari, M.K. Jha, Design and technology for greenhouse cooling in tropical and subtropical regions: a review. Energy Build. 41(12), 1269-1275 (2009). https://doi.org/10.1016/ j.enbuild.2009.08.003

8. N. Bouazizi et al., Development of new composite fibers with excellent UV radiation protection. Phys. E Low-Dimension. Syst. Nanostruct. 118, 2020 (2019). https://doi.org/10.1016/j.physe. 2019.113905 
9. M. Baneshi, H. Gonome, S. Maruyama, Wide-range spectral measurement of radiative properties of commercial greenhouse covering plastics and their impacts into the energy management in a greenhouse. Energy 210, 118535 (2020). https://doi.org/ 10.1016/j.energy.2020.118535

10. F Geoola, Solar radiation transmission of Greenhouse cladding materials, pp. 109-116 (2000)

11. R.N. Khramov, E. Biophysics, V.D. Kreslavskii, A.A. Kosobryukhov, Influence of photoluminophore-modified agro textile spunbond on growth and photosynthesis of cabbage and lettuce plants. Opt. Express 27, 31967-31977 (2019). https://doi.org/ 10.1364/OE.27.031967

12. I.V. Pollet, J.G. Pieters, Condensation and radiation transmittance of greenhouse cladding materials: part 1, laboratory measuring unit and performance. J. Agric. Eng. Res. 74(4), 369-377 (1999). https://doi.org/10.1006/jaer.1999.0475

13. S. Davis, L. Capjack, N. Kerr, R. Fedosejevs, Clothing as protection from ultraviolet radiation: which fabric is most effective? Int. J. Dermatol. 36(5), 374-379 (1997). https://doi.org/10.1046/j. 1365-4362.1997.00046.x

14. A. Petchsuk, D. Srinun, S. Buchatip, W. Supmak, D. Sirikittikul, Development of multifunctional film for greenhouse applications in tropical regions. Adv. Mater. Sci. Eng. (2019). https://doi.org/ 10.1155/2019/1692126

15. P.D. Dubrovski, D. Golob, Effects of woven fabric construction and color on ultraviolet protection. Text. Res. J. 79(4), 351-359 (2009). https://doi.org/10.1177/0040517508090490

16. M. Möller, S. Cohen, M. Pirkner, Y. Israeli, J. Tanny, Transmission of short-wave radiation by agricultural screens. Biosyst. Eng. 107(4), 317-327 (2010). https://doi.org/10.1016/j.biosy stemseng.2010.09.005

17. S.K. Agrawal, Application of textile in agriculture. Int. J. Adv. Res. Sci. Eng. 8354(2), 9-18 (2013)

18. A. Majumdar, A. Das, P. Hatua, Effects of fabric thickness and inter-yarn pore size on ultraviolet radiation protection by polyester woven fabrics. Fibers Polym. 16(5), 1163-1168 (2015). https://doi.org/10.1007/s12221-015-1163-X

19. A. Majumdar, A. Das, P. Hatua, Ultraviolet radiation protection by cotton fabrics: role of porous yarn structure, fabric thickness and pore size. J. Text. Inst. 107(9), 1159-1168 (2016). https://doi.org/10.1080/00405000.2015.1097085

20. J.M. Menter, K.L. Hatch, Clothing as solar radiation protection. Elsner P Hatch K Wigger-Alberti W Text. Ski. 31, 50-63 (2003)

21. E.A. Elnashar, Volume porosity and permeability in double-layer woven fabrics. Autex Res. J. 5(4), 207-218 (2005)

22. B. Hamza et al., Physico-chemical and mechanical characterization of Jute fabrics for civil engineering applications. J. Comput. Methods Sci. Eng. 18(1), 129-147 (2018). https://doi.org/ $10.3233 / \mathrm{jcm}-180776$

23. Z. Ahmad, M. Eldeeb, S. Iqbal, A.A. Mazari, Effect of yarn structure on cover factor in woven fabrics. Ind. Textila 69(3), 197-201 (2018)

24. M. Tàpias, M. Ralló, J. Escofet, I. Algaba, A. Riva, Objective measure of woven fabric's cover factor by image processing. Text. Res. J. 80(1), 35-44 (2010). https://doi.org/10.1177/ 0040517509104471
25. E. Schettini, G. Vox, E. Science, Variation of physical properties of LDPE greenhouse films due to agrochemicals used during cultivation. J. Agric. Eng. XLIV, 231-233 (2013). https://doi.org/ 10.4081/jae.2013.s2.e46

26. K. Yildirim, A. Kanber, M. Karahan, N. Karahan, The solar properties of fabrics produced using different weft yarns. Text. Res. J. 88(13), 1543-1558 (2018). https://doi.org/10.1177/00 40517517712095

27. A. Axelevitch, B. Gorenstein, G. Golan, Investigation of optical transmission in thin metal films. Phys. Proc. 32, 1-13 (2012). https://doi.org/10.1016/j.phpro.2012.03.510

28. O. Deulf et al., Radiometric and thermal properties of, and testing methods for, greenhouse covering materials. Acta Hortic. 2(1), 1-12 (2019). https://doi.org/10.1017/CBO9781107415324.004

29. S. Ghosh, R. Das, S. Maity, Optimization of material and process parameters of fibrous quilt for comfortable heat loss from human body. J. Text. Inst. 110(6), 873-881 (2019). https://doi.org/10.1080/ 00405000.2018 .1531742

30. T. Textiles, F. Test, Standard Test Method for Breaking Strength and Elongation of Textile Fabrics Grab, vol. 09, no. Reapproved 2013, pp. 1-8 (2015). https://doi.org/10.1520/D5035-11R15.2

31. R.A. Fisher, Statistical Methods for Research Workers (1950)

32. C. Lamnatou, D. Chemisana, Solar radiation manipulations and their role in greenhouse claddings: fluorescent solar concentrators, photoselective and other materials. Renew. Sustain. Energy Rev. 27, 175-190 (2013). https://doi.org/10.1016/j.rser. 2013.06.052

33. C. Maraveas, Environmental sustainability of greenhouse covering materials. Sustainability 11(21), 6129 (2019). https:// doi.org/10.3390/su11216129

34. T. Wei, Study on the shading property of the fabric. Adv. Mater. Res. 502, 287-291 (2012).

35. H. Zhang, T. Hu, J. Zhang, Transmittance of infrared radiation through fabric in the range 8-14 $\mu \mathrm{m}$. Text. Res. J. 80(15), 1516-1521 (2010). https://doi.org/10.1177/0040517507079783

36. M.T. Hoque, B. Mahltig, Realisation of polyester fabrics with low transmission for ultraviolet light. Color. Technol. (2020). https://doi.org/10.1111/cote. 12470

37. K. Yildirim, A. Kanber, M. Karahan, N. Karahan, The solar properties of fabrics produced using different weft yarns. Text. Res. J. 0, 1-16 (2017). https://doi.org/10.1177/004051751 7712095

38. L. Hes, A. Mihai, M. Ursache, Thermal insulation and thermal contact properties of upholstered leather furniture in wet state. Leather Footwear 67, 13-17 (2018)

39. M. Abitha Roshanara, V. Subramaniam, Review on thermal conductivity of fabrics. Appl. Mech. Mater. 813-814, 787-790 (2015).

40. I.S. Fahim, W. Mamdouh, H.G. Salem, Effect of processing technique on LDPE thin films and sheets. Int. J. Eng. Invent. 4(12), 1-05 (2015)

Publisher's Note Springer Nature remains neutral with regard to jurisdictional claims in published maps and institutional affiliations. 